\title{
Mitigating Cyber-Haram: Deradicalising Smart-Phone Non-Users in North Eastern Nigeria from Violent Extremism and Terrorism Tendencies Using Technology-Based Behavioral Theoretical Frameworks
}

\author{
${ }^{1}$ Adegbenro, R.D, ${ }^{2}$ Okolo, O., ${ }^{3}$ Longe, O.B., ${ }^{4}$ Wada, F.J \& ${ }^{5}$ Danquah, P.A. \& ${ }^{6}$ Onawola, H.J. \\ ${ }^{1}$ Information Systems Unit, ${ }^{2}$ Information Literacy Unit ${ }^{386}$ Information Systems Department \\ American University of Nigeria, Yola, Adamawa State, Nigeria \\ 4Barney School of Business, University of Hartford, West Hartford, CT 06117 \\ ${ }^{5}$ Council for Scientific and Industrial Research (CSIR-INSTI), Accra, Ghana \\ E-mails: 1 dimeji.adegbenro@aun.edu.ng; 2 omachi.okolo@aun.edu.ng; 3olumide.longe@aun.edu.ng, \\ 4Wada@hartford.edu; ${ }^{5}$ danquahpaul@gmail.com
}

\begin{abstract}
This paper evaluates the relationship between non-smart phone users among socially disadvantaged youths such as the ones found in IDPs and Almajiris in northern Nigeria and the chance of being radicalized into violent extremist groups. Employing cognitive and rational choice theory as the overarching frameworks, we sought to inquire the extent of radicalization among socially disadvantage youths, the process involved in the recruitment process, as well as the motivation behind the influx of youth into violent extremist groups. We highlight the implication of radicalized youth to the society and propose a de-radicalization framework that can be adopted to mitigate violent extremism.
\end{abstract}

Keywords: Terrorism, Ideologies, IDPs, Extremist, Violence, Youths, Smart Phones, Non Users, Almajiri.

$2^{\text {th }}$ iSTEAMS Trans-Atlantic Multidisciplinary Conference Proceedings Reference Format

Adegbenro, R.D, Okolo, O., Longe, O.B., Wada, F.J \& Danquah, P.A. \& Onawola, H.J (2020 Mitigating Cyber-Haram: Deradicalising Smart-Phone NonUsers in North Eastern Nigeria from Violent Extremism and Terrorism Using Technology-Based Behavioral Theoretical Frameworks. Proceedings of the 25th iSTEAMS Trans-Atlantic Multidisciplinary Virtual Conference, Laboratoire Jean Kuntzmann, Universite Laboratoire Jean Kuntzmann, Universite Grenoble, Alpes, France June - July, 2020. Pp 97-104. www.isteams.net/France2020.

\section{INTRODUCTION}

Terrorism is part of the broader violent extremism phenomena, thus there is a need to understand the underlying factors promoting terrorism among communities or individuals. Terrorism has had negative impacts on the society and on national development; therefore, it is imperative to initiate a counter strategy to reduce the impact of radicalization among youths, especially in the north eastern region of Nigeria. Research in violent extremism and radicalization though prolific and broad, need further ingenious approach to catch up with its evolving and dynamic dimensions. It is true that the use of mobile phones have revolutionalized our lives, and previous researches have shed more light regarding its advantages such as efficient communication, improved social coherence, improved mobile banking, opportunities for mobile phone repairers and other subsidiary businesses an honest means of livelihood (Dunn et al., 2013). Certainly, mobile phones enable us bond socially and aids in preserving societal coherence and has become a vital tool for societal merger. 
Mobile phone multi-functionalities and portability has in recent time appeals itself to consumers, and even seeking to replace computers. Smart phone unanimous acceptance and ubiquity has created a radical impact in the society. However, there is paucity of attention in respect of the group of people who as a result of Sociocultural or other subjective antecedents shy away from the adoption and use of these technologies (practicing cyber-haram). The temptation arising from this scenario is to think that IT Non-users are immuned from any form of IT abuse both behaviorally and in relation to the consequences.

The challenge with this assumption is premised on the fact that studies have also found that a sizeable number of non-users are prone to isolation, reclusion, loneliness, distractions, addiction and other forms of behavioral issues suffered by IT users (Pedrero-Pérez et al., 2019). According to Glazzard \& Zeuthen (2018), mobile phones have also created a dark platform where the social-economically disadvantaged youth and underrepresented group are lured into violent crimes. Our focus in this discourse is that these behavioral issues can be explored by recruiters to lure IT non-users into anti-social vices including extreme violence and terrorism, as in the case of north-eastern Nigeria (Pedrero-Pérez et al., 2019).

To unearth a terrorism-embedded in socio-economic and behavioural practice (Cyber-haram) that is plaguing the north-eastern Nigeria in a covert mode, we aim to establish a set of sociodemographic variables and indicators for IT non-users that explore the possibility that non-usage of IT can be leveraged upon to coarse non-users into joining terrorist groups, these variables are: cyber illiteracy, socio-economic and cultural innuendos, IT skills gaps, unhygienic cyber practices, subtle antecedents as well as offers of employment and IT training for the target group are explored by recruiters as vulnerabilities that can be explored to lure and recruit them into terrorist groups.

The dynamics of the interaction and efforts of this research is important to unravelling the understanding of the under-researched strategies used by terrorist organizations such as Boko Haram to recruit members into their group (Maza et al., 2020). Our effort would seek to produce outcomes that are supposed to unmask cyberilliteracy (cyber-haram) as a force that can be leveraged upon by terrorist groups to fan their nefarious activities into flame in northern Nigeria.

This study expose the latent and active dangers posed by a lack of attention to cyber-haram as a vulnerability that can be used to recruit IT Non-users into terrorist enclaves and advice on holistic inclusion strategies that can be adopted to mitigate the challenges identified. The impetus of this paper is to uncover the nature of this new form of radicalization in the society and propose a de-radicalization framework that can be adopted to mitigate violent extremisms.

The rest of the paper is organized as follows, in section two we review related literature, in section three we present the research problem, objectives and research questions. In section four we present the research model. In section five we present the conclusion and future work. 


\section{REVIEW OF RELATED LITERATURE}

The cyber-haram is new way of covert radicalization in the north-eastern region of Nigeria. The target populations for this form of radicalization are the youth and the under-represented group. Therefore, we review this new form of recruitment strategy and the impact on the under-represented froups.

\subsection{New form of Boko haram terrorist recruitment strategy}

There is no universally accepted stragey for terrorism recruitment, the strategy mostly employed by them are usually clandenstine and change with time and technology. These recruitment strategies could be to coercive or non-coercive, they also exploit the various loop-holes in socio-economic, ideological, psychological, and political situations to lure individuals into becoming the member of terror groups (Jones, 2017). These challenges enabled them to create the false perception among individuals and targeted groups leading them to believe that they can provide a better alternative. Societal problems and weak establishment are incubators of violent movement, these movements are inherently anti-government, anti-status quo, and anti-education, and by this circumstance creating a false sense of better conditions and living standards (Prud'homme, 2019).

Mccullough and Schomerus (2017), postulate that violent extremist is aggravated by ideologies, enabling environment, grievances and support structures, social marginalization, economic marginalization, rejection, lack of self-esteem, cultural alienation which is deeply rooted in the sense of the victimized or strong disagreement due to personal disaffection. These scenarios lead those affected by these inequalities to seek a different path in life which is usually violent or criminal in nature.

Verkasalo et al (2010), investigated the combined population of user and non-user of smart phone and the attendant health problem within a wide socio-dynamics population in Spain. Random stratified sampling was used to study a diverse population of men and women and underprivileged social class, residence in less developed districts, and a lower education level. The findings of the research showed that non-user of smart phone are not exempted from some particular set of ailment laregely attributed to smart phone users. Our current study relates to this study by adducing that those non-users of smart phones has a dimesnsion of sociological and ideological disease such as violent extremism which stemmed from their social exclusion.

Study on the intention on use and non-use of smart phone mobile applications using an online survey method to obtain data, in order to investigate the relationship with extremist. The study revealed that technological barriers were the reasons why some people do not use smart phone and that most people use technology because of expected usefulness and enjoyment (Hsu \& Lin, 2008). The situations in the north east region of Nigeria have exploited socio-economic and skill gaps issues as a bait to lure vulnerable youths to join their group, this largely under-researched area would be a topical point for this study.

\subsection{Under-represented Groups and Radicalization}

Government, religious groups, Non-Governmental organizations, institutions, and other actors against terrorism has been addressing issues related to youth radicalization into extremist group by majorly focusing on youth vulnerabilities to radical influences (Nivette et al., 2017). Youth ebullience and exuberance has made them a strong force in the society, this youful strength is exploited by most viable industry that wants to scceed. Young people are vulnerable to various influences during the adolescent stage due to peer pressure and inclination to experiment new ideas, and if they perceive themselves as victims of social isolation, victimization, social exclusion, rejection or marginalization, they are most at risk of recruitment into violent groups (Mona et al., 2016). 
The large percentage of violent crimes are perpetrated by the youth, therefore, terrorists group have deviced various avenues for youth inclusion in terrorism. The social-economic disadvantage and deprivation of so many youth in the north-eastern Nigeria have ignited their vulnerabilities and eventual recruitment into terrorist group. A lot of educational, political, social and sport related activities have being organized in some internally displaced camps (IDPs) for youth in order to improve youth resistance to radicalization. This work focuses on the non-smart phone users who feel isolated and has become grounds for radicalization.

\section{RESEARCH PROBLEM}

Several studies have focused on terrorism in the north-eastern Nigeria, however, the understanding of strategies used by the terrorist organizations to recruit members remains largely under-researched (Maza et al., 2020). There is a need to explain the complexities of extremist radicalization process and the underlying factors, especially the one that exploit the youth socio-economic vulnerabilities. Violent extremism have been a major challenge in North-eastern Nigeria and the world at large, it has led to the loss of tens of thousand of lifes in Nigeria since 2014 (Alao et al., 2019; Campbell \& Harwood, 2018 ). Extant literature on terrorism postulated that economic, social and cultural values are indirectly connected to radicalization process. This research is poised to investigate the role of socio-economic, psychological and cultural variables among non-smart phone users that have lured vulnerable groups like the Almajiri and youth in the IDP camps into the extremist group.

The new emerging finding in terrorist recutiment steategy have shown that recruiters diesignate camps for training on the use of computers, distribution of smart phones and other palliatives. They gave potential recuits a false hope of luxurious life and the promise of smart phone which they have been deprived. Socio-economic, cyber illiteracy, illusion of better life and desperation to improve their status have provided fruitful grounds for the deceit suffered by potentials recruits, this need to be investigated (Zhao et al., 2019).

The potential of how a non-smart phone user can be radicalized remain an unexplored topic in violent extremism. Youth radicalization remain a subject of discourse since socio-econmic disadvantage and other attendant factors like loneliness, environmental pressure, peer pressure, fear of been left out, psychological justification, and personality traits have been a breeding grounds for radicalization. There are no indications of systematic efforts in north eastern part of Nigeria to determine how these factors identified above impinge on the possibility of been lured into terrorist group (Alao et al., 2019). This is a new and emerging new frontier in the radicalization process that needs to be explored. These new issues raised need to be proper investigated in order to understand the subtle manner the terrorist are now using to expand their reach and populate their foot soldiers.

\subsection{Research Aims and Objectives}

This research sets out to explore how the non-users of smart phones are vulnerable to radicalization and the process undertaken by terrorist during recruitment. The specific objectives are:

3. Determine the nature of recruitment patterns, recruiters strategies for recruiting under-represented groups into terrorists' groups in North Eastern Nigeria

4. Identify how the socio-economic and technological know-how can be leveraged by terrorist to lure potential targets into their group.

5. Suggest a new framework for counter-terrorism basd on the new trend of terrorism identified (cyberharam). 


\subsection{Research Questions}

4. How does cyber illiteracy and non-use of other IT devices like smart phone be used to radicalize?

5. How does socio-economic and cultural isses contribute to radicalization?

\subsection{Target Groups/scope of the study}

The target groups for this research are non-smart phone users, Almajiri, internally displaced people in camps, the youth and other vulnerable groups susceptible to cyber-haram, infiltration by terrorist and likely to be invited to join terrorist and violent extremist group.

\subsection{Direct Beneficiaries}

This research would be valuable to security agencies, counter terrorism group and other policy experts interested in counter-radicalization.

\section{RESEARCH MODEL}

We adopted cognitive and rational choice theory to discuss why people join violent groups. Scholars and policy analysts have published numerous theories and studies that attempt to explain radicalization. These theories range builds on variables such as individual, psychological mechanisms, as well as mass societal strains. Psychological and cognitive theories claim that radicalization is the result of individual psychologies, personalities, and choices (Nwafor \& Nwogu, 2015). Rational choice theory contends that people choose terrorism because it is the best available option to affect change. Others argue that joining a terrorist movement offers an "identity stabilizer" for people with low self-esteem or for those who, as excluded minorities, are searching for belonging as a way to consolidate and defend their identity. Still others attempt to generalize from prior research, which finds that cognitive function controls violent behavior and cognitive style influences aggressive behavior (Trip et al., 2019).

Therefore, some peoples' cognitive functions may make them more likely to sympathize with violent terrorist groups when pursuing social or political agendas. Another cognitive theory states that terrorists are novelty seekers and are attracted to terrorism for the thrill of action. By contrast, sociological theories argue that societal forces are radicalizing mechanisms (Nwafor \& Nwogu, 2015). Albert Bandura's social learning theory argues that people who live in violent regions and who witness terrorism regularly may seek to imitate terrorists or learn from a culture that glorifies terrorists (Clubb \& Tapley, 2018).

National cultural theory suggests that national cultures are either "collectivist" or "individualist." Collectivists divide the world into groups and out-groups and are more likely to attack "outsiders" to defend the in-group, while individualists are more likely to attack their own people (Bloom \& Matfess, 2014). Relative deprivation and oppression theories contend that people who are politically and economically oppressed turn to violence for change. Other sociological theories contend that radicalization is facilitated through social networks and active recruitment by terrorist movements. Social movement theory explains that terrorist movements adapt to political opportunities and constraints and mobilize resources to frame the group's ideology or narrative in a way that will attract new followers (Salifu \& Ewi, 2017). Strategic propaganda on the Internet and charismatic recruiters convince people that the movement has solutions to society's problems. Social network theory similarly contends that radicalization is a group process where extremist individuals radicalize other people within their social networks (Johnson \& Robinson, 2018). 


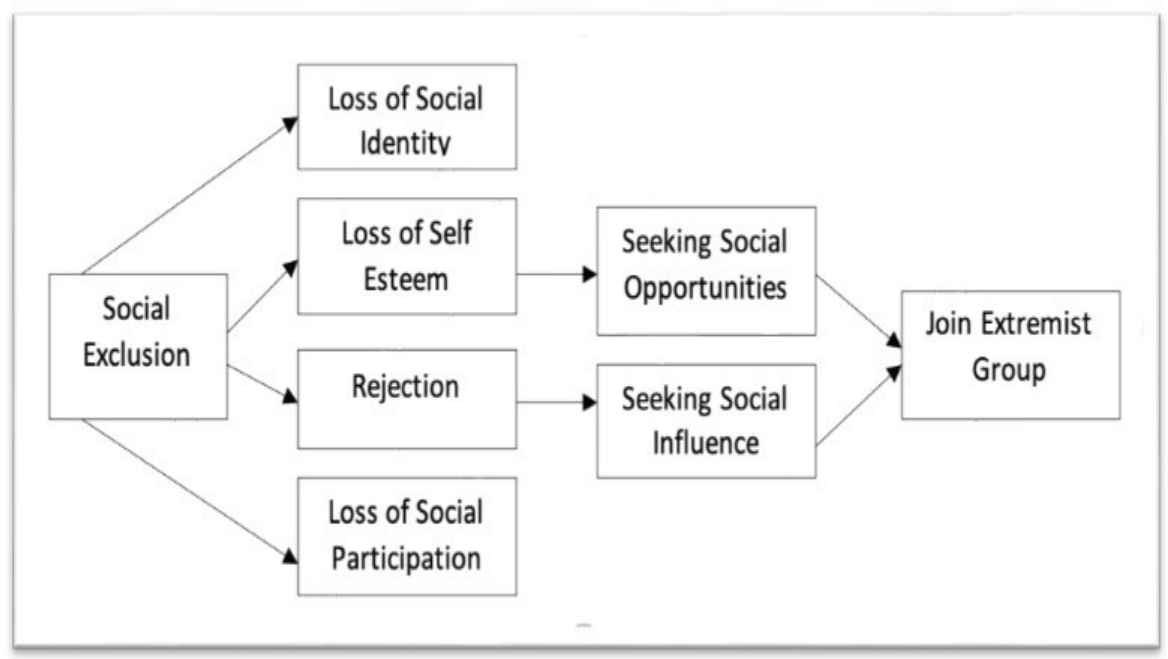

Fig 1: Conceptual Framework for causes of cyber haram Source: Authors Conceptualization

Conceptual model proposed will answer the research questions raised by the researcher; each of the variables in the model has a major role to play in the radicalization of under-represented group.

\subsection{Social Exclusion}

The first dimension of extremist is the exclusion from social positions and values that are perceived important to the people. Social exclusion is a form of discrimination in which individual are denied access to opportunities, resources, social life and various rights available to other member of the society, and are important to social integration and observance of human right. Social exclusion from the society increases the chance of being radicalize due to loss of social identity and social value (Alao et al., 2019).

\subsection{Loss of Social Identity}

The second dimension of violent extremism is the Loss of social identity among socially disadvantaged groups. When people are socially excluded from the society due to economic, social and psychological reasons, the resultant effect is the loss of social identity. This can lead to fear of being left out among the people. Youth responds sharply to this exclusion and would do anything to attain their identity in the society, this is because when this happens they always feel isolated, betrayed and depressed, which is a criteria extremist used in gaining advantage and winning them over to their side. Violent extremist most times offers such vulnerable individual fake sense of economic stability, new social status and propensity of being forcefully respected due to his new extremist nature.

\subsection{Cultural Rejection}

The third dimension of violent extremism is the rejection of cultural values and norms that are not perceived as indigenous to the society tradition. The initial misinformed cultural problem in the north-eastern Nigeria is to denounce education as being alien to northern Islamic cultures; therefore effort was made by the insurgent to outlaw education as abominable. 
In constrast, the use of smart phones and other information technology devices largely referred as to as foreign culture are been used to lure the socio-economic disadvantage youth to join terrorist groups.

\subsection{Lack of social participation}

The fourth dimension of the reason people join violent extremist group is the lack avenues for social participation. Youth without access to smart phone in the community feels isolated from their age groups and peers. They seek alternative means to reconnect socially and feel included, this alternative avenues makes them vulnerable and easy recruits for extremist.

\section{RESEARCH DIRECTION}

We intend to present a research framework based on cognitive and rational choice theory to inquire the concept of cyber-haram as sitauated in this study, we would also investigate the extent of radicalization (cyber-haram motivated) among the socially disadvantage youth in the north eastern region of Nigeria, the process involved in the recruitment process, as well as the motivation behind the influx of youth into violent this type of extremist groups.

\section{CONCLUDING REMARKS}

In this paper we conceptualize the nascent and an overlooked kind of terrorism (Cyber-haram) exhibited in the north-eastern region of Nigeria. We hope to adopt two theories such as cognitive and rational choice theory as well as their constructs to understand cyber-haram and frame the model.

Future studies would intend to test the theories adopted and coming up with a new framework for cyber-haram.

\section{REFERENCES}

1. Alao, D. O., Osah, G., \& Adam, E. M. (2019). Unabated Cyber Terrorism and Human Security in Nigeria. Asian Social Science, 15(11), 105. https://doi.org/10.5539/ass.v15n11p105

2. Bélanger, J. J., Moyano, M., Muhammad, H., Richardson, L., Lafrenière, M. A. K., McCaffery, P., Framand, K., \& Nociti, N. (2019). Radicalization leading to violence: A test of the $3 \mathrm{~N}$ model. Frontiers in Psychiatry, 10(FEB), 1-12. https://doi.org/10.3389/fpsyt.2019.00042

3. Bloom, M., \& Matfess, H. (2014). Women as Symbols and Swords in Boko Haram's Terror. Prism: A Journal of the Center for Complex Operations, 6(1), 105-121.

4. Clubb, G., \& Tapley, M. (2018). Conceptualising de-radicalisation and former combatant reintegration in Nigeria. Third World Quarterly, 39(11), 2053-2068.

https://doi.org/10.1080/01436597.2018.1458303

5. Dunn, B. K., Galletta, D. F., Hypolite, D., Puri, A., \& Raghuwanshi, S. (2013). Development of smart phone usability benchmarking tasks. Proceedings of the Annual Hawaii International Conference on System Sciences, 1046-1052. https://doi.org/10.1109/HICSS.2013.177

6. Glazzard, A., \& Zeuthen, M. (2018). Violent Extremism. Violent Extremism, 34. https://doi.org/10.4018/978-1-5225-7119-3

7. Hsu, C. L., \& Lin, J. C. C. (2008). Acceptance of blog usage: The roles of technology acceptance, social influence and knowledge sharing motivation. Information and Management, 45(1), 65-74. https://doi.org/10.1016/j.im.2007.11.001 
8. Johnson, I. D., \& Robinson, G. E. (2018). Naval Postgraduate School Monterey, California Thesis Lessons in Ideology: a Study of the Relationship Between Formal Education, Socialization, and Violent Extremism.

9. Jones, E. (2017). The reception of broadcast terrorism: recruitment and radicalisation. International Review of Psychiatry, 29(4), 320-326. https://doi.org/10.1080/09540261.2017.1343529

10. Kruglanski, A., Jasko, K., Webber, D., Chernikova, M., \& Molinario, E. (2018). The making of violent extremists. Review of General Psychology, 22(1), 107-120. https://doi.org/10.1037/gpr0000144

11. Maza, K. D., Koldas, U., \& Aksit, S. (2020). Challenges of Countering Terrorist Recruitment in the Lake Chad Region: The Case of Boko Haram. Religions, 11(2), 96. https://doi.org/10.3390/rel11020096

12. Mccullough, A., \& Schomerus, M. (2017). What do we know about drivers of radicalisation and violent extremism, globally and in Niger? February.

13. Mona, A., Rajneesh, N., \& Andrea, M.-N. (2016). How do collaboration and investments in knowledge management affect process innovation in services? Journal of Knowledge Management, 20(5), 1004-1024. https://doi.org/doi:10.1108/JKM-11-2015-0429

14. Ndungu, I., \& Salifu, U. (2017). The role of women in violent extremism in Kenya. May, 1-16.

15. Nivette, A., Eisner, M., \& Ribeaud, D. (2017). Developmental Predictors of Violent Extremist Attitudes: A Test of General Strain Theory. Journal of Research in Crime and Delinquency, 54(6), 755-790. https://doi.org/10.1177/0022427817699035

16. Nwafor, N. H. A., \& Nwogu, G. A. I. (2015). Implication of Radicalisation for Nigerian Education: A Philosophical Analysis. Journal of Education and Practice, 6(21), 201-207.

17. Pedrero-Pérez, E. J., Morales-Alonso, S., Rodríguez-Rives, E., Díaz-Olalla, J. M., Álvarez-Crespo, B., \& Benítez-Robredo, M. T. (2019). Smartphone nonusers: Associated sociodemographic and health variables. Cyberpsychology, Behavior, and Social Networking, 22(9), 597-603. https://doi.org/10.1089/cyber.2019.0130

18. Prud'homme, J. (2019). Security, Religion, and Political Culture: A Defense of Weak Disestablishment. Religions, 10(2), 88. https://doi.org/10.3390/rel10020088

19. Salifu, U., \& Ewi, M. (2017). Boko Haram and violent extremism, perspectives from peacebuilders. Iss, February, 1-16.

20. Trip, S., Bora, C. H., Marian, M., Halmajan, A., \& Drugas, M. I. (2019). Psychological mechanisms involved in radicalization and extremism. A rational emotive behavioral conceptualization. Frontiers in Psychology, 10(MAR). https://doi.org/10.3389/fpsyg.2019.00437

21. Verkasalo, H., López-Nicolás, C., Molina-Castillo, F. J., \& Bouwman, H. (2010). Analysis of users and non-users of smartphone applications. Telematics and Informatics, 27(3), 242-255. https://doi.org/10.1016/j.tele.2009.11.001

22. Zhao, S., Li, S., Ramos, J., Luo, Z., Jiang, Z., Dey, A. K., \& Pan, G. (2019). User profiling from their use of smartphone applications: A survey. Pervasive and Mobile Computing, 59, 101052. https://doi.org/10.1016/j.pmcj.2019.101052 